\title{
Assessment of the organoleptic properties, species delimits and varietal identities of pennyworts in Sri Lanka
}

\author{
HSM Jayarathne ${ }^{1}$, LT Ranaweera ${ }^{1}$, THI Gayathree ${ }^{1}$, SI Karunarathne ${ }^{1}$, GKS Aananda ${ }^{1}$, RDGA \\ Ranasinghe $^{1}$, SMNM Thilakarathne ${ }^{1}$, WWMUK Wijesundara ${ }^{1}$, CK Weebadde $^{2}$ and SDSS \\ Sooriyapathirana ${ }^{1,3^{*}}$ \\ ${ }^{I}$ Department of Molecular Biology and Biotechnology, Faculty of Science, University of Peradeniya, Peradeniya. \\ ${ }^{2}$ Department of Plant, Soil and Microbial Sciences, College of Agriculture and Natural Resources, Michigan State University, East Lansing, 48824, \\ USA. \\ ${ }^{3}$ Postgraduate Institute of Science, University of Peradeniya, Peradeniya.
}

\begin{abstract}
Asiatic pennyworts (AP) (Centella asiatica) are among the most popular leafy vegetable species in Sri Lanka. Five AP cultivars, namely, Lowland AP (LAP), Giant AP1 (GAP1), Giant AP2 (GAP2), Salad AP (SAP), and Medicinal AP (MAP) are grown in the country. Two other leafy vegetable species, water pennyworts (WP) (Hydrocotyle verticillata) and Korean pennyworts (KP) (Adenophora triphylla), are also designated under 'pennyworts' in Sri Lanka. The consumerpreference on the pennywort bunches available in the market and the salad properties are yet to be studied. Also, no attempts have been reported for the identification of species delimits and phylogenetic relationships among the different cultivars of $C$. asiatica. In the present study, consumer preference on the appearance of leaf bunches and salads of pennyworts were assessed. The intra- and interspecific variation of pennyworts grown in Sri Lanka were also studied. The genomic DNA extracted from the immature leaves was PCR amplified for the DNA barcoding markers matK-trnT, atpB-rbcL, and $r b c L$. The PCR products were sequenced and used to assess the intraand interspecific variation. The consumers mostly preferred to purchase the leaf bunches of GAP2 because of its large leaf size and appealing look. However, the highest preference for salads was reported for the dishes prepared using LAP, MAP, and WP. The clade structure of the phylogenetic tree drawn for AP cultivars shows an intraspecific variation. Our study also highlights the importance of producing an improved AP cultivar with larger leaf size, improved flavor properties, and sinuate leaf margin.
\end{abstract}

Keywords: Adenophora triphylla, Centella asiatica, DNA barcoding of Centella asiatica, Hydrocotyle verticillata, Indian pennyworts, water pennywort.

\section{INTRODUCTION}

Asiatic pennyworts (APs) (Centella asiatica L. Urban of family Apiaceae), commonly known as Gotukola or Indian pennyworts, are among the most popular leafy vegetables in Sri Lanka (Nadeeshani et al., 2018). APs are popular in South East Asia (Chandrika \& Kumar, 2015) however; it has a limited recognition in other countries. AP is mainly consumed as a salad. AP leaf extracts are also consumed as porridge, a frequently consumed herbal drink in Sri Lankan breakfasts. AP is also used to prepare herbal tea, which is a rich source of antioxidants (Huda-Faujan et al., 2007). C. asiatica is well adapted to tropical and subtropical climates and predominantly grown in countries such as Sri Lanka, India, China, Madagascar, and Indonesia (Jamil et al., 2007). In addition to $C$. asiatica two other pennywort species, Hydrocotyle verticillata [vern. water pennyworts (WP)] of family Araliaceae and Adenophora triphylla [vern. Korean pennyworts (KP)] of family Campanulaceae are also grown and consumed in Sri Lanka. All three

\footnotetext{
"Corresponding author (sunethuop@gmail.com; (D) https://orcid.org/0000-0002-5592-1742)
} 
pennywort species prefer to grow in moist soils (Peiris \& Kays, 1996). AP exhibits a prostrate and stoloniferous perennial growth pattern with rooting at the nodes (Bandara et al., 2011; Chandrika \& Kumara, 2015). Moreover, AP is fast-growing and listed as a potentially invasive plant in some countries (Perera, 1995; Van De Wiel et al., 2009). WP also exhibits a prostrate growth and rooting at nodes. WP can also grow as a complete aquatic plant and is occasionally used as an ornamental plant in fish tanks and water ponds. KP is generally grown in meadows and grasslands. KP thrives well in the agricultural soils where AP grows (Peiris \& Kays, 1996; Yu et al., 2006).

The fully grown leaves with petioles are the economically important part of the pennyworts. However, the whole plants with roots are also harvested to make herbal medicines and porridge preparations. The leaves are rich with carotenoids, vitamins, and minerals, including calcium, iron, potassium, and magnesium (Tiwari et al., 2000). AP leaves also contain a wide range of phytochemicals such as triterpenes, glycosides, flavonoids, carotenoids, alkaloids, volatile oils, fatty acids, and triterpenoid saponins (Singh \& Rastogi, 1969; Chandrika \& Kumara, 2015).

AP is a popular medicinal plant possessing many reported ethnomedicinal and nutritional values. Human beings have used AP since prehistoric times. AP is widely used in the ayurvedic and Chinese medicinal practices (Cesarone et al., 1992; Brinkhaus et al., 2000; Incandela et al., 2001; Singh et al., 2010; 2012) and used as an ingredient in herbal medicinal preparations for treating skin conditions (e.g., wounds, leprosy, varicose, and psoriasis), gastrointestinal diseases (e.g., diarrhea, dysentery and gastric ulcers), infectious diseases (e.g., influenza) and inflammatory diseases in the liver, urogenital and nephrological tissues (Rosen et al., 1967; Cesarone et al., 1992; Sunilkumar et al., 1998; Brinkhaus et al., 2000; Incandela et al., 2001; Singh et al., 2012).

According to the growers and agriculture workers, a total of five AP cultivars, Lowland AP (LAP), Giant AP1 (GAP1), Giant AP2 (GAP2), Salad AP (SAP), and Medicinal AP (MAP) are grown as leafy vegetables in Sri Lanka. The consumers have diverse preferences over the different AP cultivars. There are attractive AP cultivars for their gorgeous foliage and pleasing taste when prepared as salads. The AP cultivars with attractive foliage also have export potential. However, consumer preference on leaf bunches and the culinary preparations of the AP, WP, and KP in Sri Lanka have not been assessed. Moreover, the species delimits among AP, WP, and KP, and the intraspecific variation within AP have not been assessed based on the molecular phylogenetics. In export industry, it is essential to establish the DNA barcodes of the exportable AP cultivars for authentication and validation purposes (Hebert et al., 2003; Chase et al., 2005; Mitchel, 2008; Hollingsworth et al., 2011). Therefore, the present study was aimed at assessing the consumer preference on the appearance of leaf bunches, salads of AP cultivars, WP, and KP. the phylogenetic relationships and intraspecific variations of AP cultivars grown in Sri Lanka were also studied to facilitate germplasm conservation, and future crop breeding programs.

\section{METHODOLOGY}

\section{Plant material and observations of morphological features}

A total of five AP cultivars (LAP, GAP1, GAP2, SAP, and MAP) were assessed in the present study. WP and $\mathrm{KP}$ were also included in the analyses. Samples were collected from the Green Leaf Vegetable Collection available at the Department of Agriculture, Gannoruwa, Peradeniya, Sri Lanka (GPS: 7.276292, 80.599033) and University of Peradeniya, Sri Lanka (GPS: 7.259434, $80.598400)$. The voucher numbers, sample details and the GenBank IDs of the DNA sequences generated are given in Table 1. All cultivars were established in a greenhouse at the University of Peradeniya, Sri Lanka (GPS: 7.259434, 80.598400) according to the recommendations provided by the Department of Agriculture, Sri Lanka. The standard compost mixtures were prepared according to the procedures given in http://www.agrimin.gov.lk/ (Department of Agriculture, Sri Lanka) and used for planting in the mixture of 1:1:1 compost, garden soil, and sand, respectively. The basal dressing was applied as the rate of $110 \mathrm{~kg} / \mathrm{ha}$ of urea, 275 $\mathrm{kg} / \mathrm{ha}$ of Triple Super Phosphate (TSP) and $75 \mathrm{~kg} / \mathrm{ha}$ of Murate of Potash (MOP). The subsequent dressings were made monthly in which TSP and MOP were only added at two-month intervals whereas urea was added monthly. The fertilizer amounts were similar to basal dressing. The temperature range of the greenhouse was from $22{ }^{\circ} \mathrm{C}$ to $36{ }^{\circ} \mathrm{C}$ (mean $32{ }^{\circ} \mathrm{C}$ ) and mean relative humidity was $67 \%$. The photosynthetically active radiation (PAR) within greenhouse was measured using MultispeQ V.2 device (https://www.photosynq.com/) and found to be in the range of 25.04 to 2982.82 . Overhead irrigation was provided on a need basis by checking the soil moisture content for field capacity. The leaves with stalks were harvested at fully grown stage for the organoleptic 
assessment of bunches and salad preparations. General morphological features were recorded to provide cultivar and species descriptions by using the representative samples of plants and harvestable leaves with stalk at maturity stage (Table 2).

Table 1: Sampling details and DNA sequence ID of the present study

\begin{tabular}{|c|c|c|c|c|c|c|}
\hline \multirow{2}{*}{$\begin{array}{l}\text { Voucher } \\
\text { No. }\end{array}$} & \multirow[t]{2}{*}{ Species } & \multirow[t]{2}{*}{ Common Name } & \multirow[t]{2}{*}{ Abbreviation } & \multicolumn{3}{|c|}{ GenBank IDs of the submitted sequences* } \\
\hline & & & & $\operatorname{mat} K-\operatorname{trn} T$ & $a t p B-r b c L$ & $r b c L$ \\
\hline DMB 89 & Centella asiatica & Giant Asiatic Pennywort 1 & GAP1 & MK905062 & MK905042 & MK905027 \\
\hline DMB 90 & & & & MK905063 & MK905043 & MK905028 \\
\hline DMB 91 & & & & MK905064 & MK905044 & - \\
\hline DMB 92 & & Giant Asiatic Pennywort 2 & GAP2 & MK905065 & MK905045 & MK905029 \\
\hline DMB 93 & & & & MK905066 & MK905046 & MK905030 \\
\hline DMB 94 & & & & MK905067 & MK905047 & - \\
\hline DMB 95 & & Lowland Asiatic Pennywort & LAP & MK905071 & MK905051 & MK905033 \\
\hline DMB 96 & & & & MK905072 & MK905052 & MK905035 \\
\hline DMB 97 & & & & MK905073 & MK905053 & - \\
\hline DMB 98 & & Salad Asiatic Pennywort & SAP & MK905077 & MK905057 & MK905038 \\
\hline DMB 99 & & & & MK905078 & MK905058 & MK905034 \\
\hline DMB 100 & & & & MK905079 & MK905059 & - \\
\hline DMB 101 & & Medicinal Asiatic & MAP & MK905074 & MK905054 & MK905036 \\
\hline DMB 102 & & Pennywort & & MK905075 & MK905055 & MK905037 \\
\hline DMB 103 & & & & MK905076 & MK905056 & - \\
\hline DMB 104 & Adenophora triphylla & Korean Pennywort & $\mathrm{KP}$ & MK905068 & MK905048 & MK905031 \\
\hline DMB 105 & & & & MK905069 & MK905049 & MK905032 \\
\hline DMB 106 & & & & MK905070 & MK905050 & - \\
\hline DMB 107 & Hydrocotyle verticillata & Water Pennywort & WP & MK905060 & MK905039 & MK905025 \\
\hline DMB 108 & & & & MK905061 & MK905040 & MK905026 \\
\hline DMB 109 & & & & MK905062 & MK905041 & - \\
\hline
\end{tabular}

"Submitted and publicly available at GenBank (https://www.ncbi.nlm.nih.gov/genbank/); due to the less divergence, only two samples from each cultivar/species were sequenced for $r b c L$.

\section{Organoleptic assessment}

\section{Preference on leaf bunches}

The harvested leaves (at fully grown stage) were prepared as bunches as they are available in the market (Figure 1). The freshly prepared bunches were presented to a group of 30 taste panellists for ranking. The recruited panellists were trained for the purpose and had extensive experience in purchasing and consuming pennyworts. The panellists were asked to rank the bunches for preferred levels of aroma, colour, glossiness, leaf shape, leaf size, leafiness and overall preference for three categories (1: low preference; 2 . moderate preference; 3 : highest preference) and provide their specific opinions.

\section{Preference on salads}

The leaf material was washed thoroughly three times with water and allowed to drain for $3 \mathrm{~h}$. The leaf material was finely chopped (1-3 mm) using a sharp knife. For $1 \mathrm{~kg}$ of chopped leaf material; $200 \mathrm{~g}$ of grated coconut, $50 \mathrm{~mL}$ of lime juice, $100 \mathrm{~g}$ of chopped onion, $20 \mathrm{~g}$ of salt and $10 \mathrm{~g}$ of black pepper powder were added. The ingredients were mixed gently with hand without squeezing the material. The preparation made in this manner is called 'pennywort salad', the most popular recipe for consuming pennyworts in Sri Lanka (Table 3). The taste panellists were given salad preparations to rank for the organoleptic parameters; aroma, bitterness, colour, texture, and overall taste and record the opinions. 
Table 2: Vegetative growth characteristics of pennyworts assessed

\begin{tabular}{|c|c|c|c|c|c|c|}
\hline $\begin{array}{l}\text { Pennywort } \\
\text { species/cultivar }\end{array}$ & Growth pattern & $\begin{array}{l}\text { Colour of root } \\
\text { stock }\end{array}$ & $\begin{array}{l}\text { Colour of } \\
\text { stolens }\end{array}$ & $\begin{array}{l}\text { Weeks to } \\
\text { runnering }\end{array}$ & $\begin{array}{c}\text { No. of leaves } \\
\text { produced by a } \\
\text { stolen }\end{array}$ & $\begin{array}{l}\text { Weeks to make } \\
\text { complete ground } \\
\text { cover (mat) }\end{array}$ \\
\hline $\begin{array}{l}\text { GAP1 } \\
\text { GAP2 } \\
\text { LAP }\end{array}$ & $\begin{array}{l}\text { Creeping and } \\
\text { horizontal stolens } \\
\text { (arise from leaf axils) } \\
\text { are grown connecting } \\
\text { the plants. }\end{array}$ & $\begin{array}{l}\text { Pale-white } \\
\text { hairy rhizome } \\
\text { (vertical } \\
\text { downward } \\
\text { growth) }\end{array}$ & $\begin{array}{l}\text { Yellowish } \\
\text { green to } \\
\text { green }\end{array}$ & $2-3$ & $3-5$ & $6-8$ \\
\hline SAP & & & & & & \\
\hline MAP & & & & & & \\
\hline KP & $\begin{array}{l}\text { Creeping and } \\
\text { horizontal stolens are } \\
\text { grown connecting } \\
\text { the plants. Plants } \\
\text { in the middle of the } \\
\text { mat display upright } \\
\text { growth. }\end{array}$ & & & & & \\
\hline WP & $\begin{array}{l}\text { Creeping and } \\
\text { horizontal stolens are } \\
\text { grown connecting the } \\
\text { plants. Also thrives } \\
\text { well in aquatic media. }\end{array}$ & & $\begin{array}{l}\text { Green leaves } \\
\text { and light } \\
\text { yellowish } \\
\text { green leaf } \\
\text { peduncles }\end{array}$ & & & \\
\hline
\end{tabular}

The panellists used the same scale that they used to rank bunches.

\section{Organoleptic data analysis}

The preference data generated for pennywort bunches and salad dishes were analysed using the statistical package SAS 9.4 (SAS Institute, Cary, NC, USA). The row percentages of significant associations were calculated for the interpretation of the relative preferences on bunch and salad of each pennywort type. The weighted scores were calculated by multiplying row percentages with the respective rank to tabulate weighted scores for all the organoleptic parameters for each pennywort type. Principal component analyses (PCA) were conducted for the weighted scores of the bunch and salad preference data separately using Minitab 16 (Minitab Inc., USA) to depict the variations in organoleptic parameters among pennywort types (Kumari et al., 2019).

\section{DNA isolation, PCR and DNA sequencing}

The immature leaves were collected and ground in liquid nitrogen to acquire fine powder samples. Genomic DNA was extracted using a modified CTAB method (Porebski et al., 1997), and the DNA samples were stored at $-20{ }^{\circ} \mathrm{C}$. The genomic DNA samples were PCR amplified with universal plant DNA barcoding markers; $r b c L$ (Pf: ATGTCACCACAAACAGAGACTAAAGC; Pr: GTAA AATCAAGTCCACCRCG) (Hoot et al., 1995; Levin et al., 2003; Kress \& Erickson, 2007), matK-trnT spacer (Pf: GCATAAATATAYTCCYGAAARATAAGTGG, Pr: TGGGTTGCTAACTCAATGG) (Wicke \& Quandt, 2009), and, atpB-rbcL (Pf: 5'GAAGTAGTAGGATT GATTCTC3', Pr: 5'TACAGTTGTCCATGTACCAG3') (Hoot et al., 2001). PCR mixtures $(30 \mu \mathrm{L})$ were prepared of with $1 \times$ Go Taq ${ }^{\circledR}$ Green Master Mix (Promega Corporation, Madison, Wisconsin, USA), $1 \mu \mathrm{L}(10 \mathrm{ng} / \mu \mathrm{L})$ of each forward and reverse primers, $7.0 \mu \mathrm{L}$ of spermidine $\left(1.34 \times 10^{-4} \mathrm{~mol} / \mathrm{dm}^{3}\right)$ and $1 \mu \mathrm{L}$ of template DNA $(60 \mathrm{ng} /$ $\mu \mathrm{L}$ ). PCR was carried out using a thermal cycler (Takara, Otsu Shiga, Japan). The thermal profile consisted initial denaturation at $95^{\circ} \mathrm{C}$ for 5 min followed by 40 cycles of denaturation at $95^{\circ} \mathrm{C}$ for $1 \mathrm{~min}$, primer annealing for 1 min at $48{ }^{\circ} \mathrm{C}$ for $m a t K$-trnT spacer, $45^{\circ} \mathrm{C}$ for atpB-rbcL spacer and $55^{\circ} \mathrm{C}$ for $r b c L$, extension at $72^{\circ} \mathrm{C}$ for $2 \mathrm{~min}$ and final extension at $72{ }^{\circ} \mathrm{C}$ for $10 \mathrm{~min}$. To visualize the PCR products, $2.5 \%$ agarose gel was used and they were purified using QIAquick ${ }^{\circledR}$ PCR Purification Kit (Catalog No: 28104, Qiagen, Hilden, Germany). The purified PCR 
products were cycle sequenced using Genetic Analyzer ABI 3500 (Applied Biosystems).

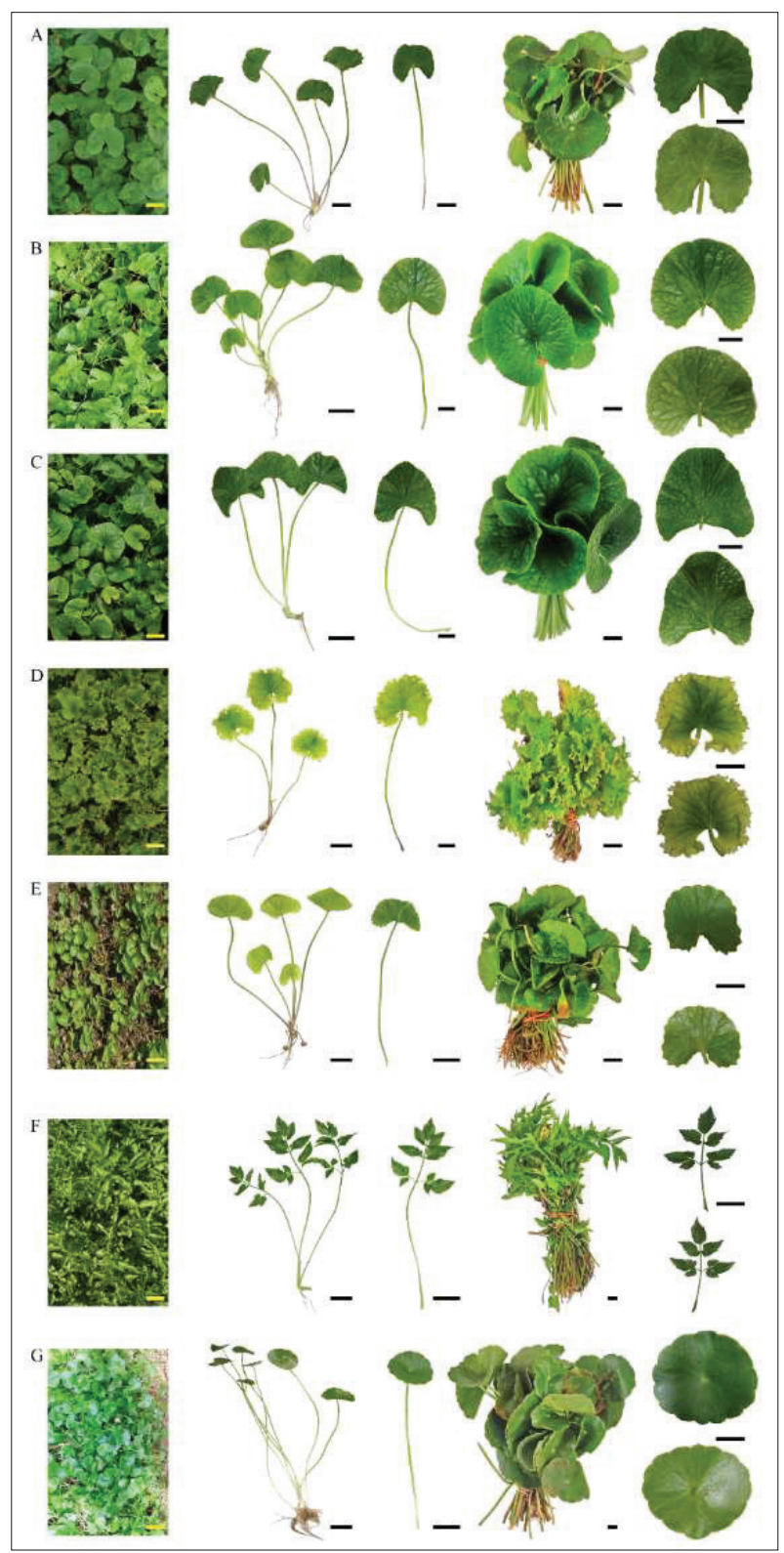

Figure 1: Morphological variation among the five AP cultivars, KP and WP. A patch of the field grown plants, separated runner, a leaf at the edible stage, a typical bunch available in the market and close-up view of the adaxial and abaxial sides of the leaves are shown. The $1 \mathrm{~cm}$ sized scale bars are separately shown to indicate the relative sizes. A: Lowland Asiatic Pennywort (LAP); B: Giant Asiatic Pennywort1 (GAP1); C: Giant Asiatic Pennywort2 (GAP2); D: Salad Asiatic Pennywort (SAP); E: Medicinal Asiatic Pennywort (MAP); F: Korean Pennywort (KP); G: Water Pennywort (WP).

\section{Phylogenetic analysis}

The raw pennywort sequence-reads were examined, and ambiguous regions were trimmed using MEGA 7 software (Kumar et al., 2016). The consensus sequences were subjected to a Basic Local Alignment Search Tool (BLAST) search in NCBI. The best hits were identified. Depending on the bit score and plant morphology, genus, and the species names were confirmed for the studied pennyworts.

Three separate alignments were built for $r b c L$, matK-trnT and atpB-rbcL in MEGA 7 to determine the phylogenetic relationships of the pennywort types. The behaviour of the clustering and concordance of the tree topologies of each marker were predetermined by implementing a partition homogeneity (ILD) test (Planet, 2006). The congruent datasets were combined and the combined dataset was used in phylogenetic tree construction. Once the datasets are combined, different markers must be differentially treated; thus, a data partition matrix was prepared in PartitionFinder 2 software in CIPRES supercomputer (Miller et al., 2010). In the data partition analysis, the best partition schemes were assessed, and the best model of evolution for the combined dataset was selected. The corrected Akaike information criteria (AICc) (Cavanaugh, 1997) were used to find the best models of evolution for each partition. The output was exported into the downstream phylogenetic analysis. A phylogenetic tree search was carried out in the Bayesian framework using MrBays (Huelsenbeck et al., 2001) in the CIPRES science gateway (Miller et al., 2010). Four Markov Chain Monte Carlo (MCMC) chains (two hot chains and two cold chains) were implemented for ten million runs, and the independent sampling from the posterior distribution was assessed using Effective Sample Size for all the priors used. The initial $10 \%$ of the trees were discarded as burn-in, and the rest of the sampled trees were used to come up with the final majority rule consensus tree. To further validate the tree topology given in the Bayesian framework, a Maximum Likelihood (ML) bootstrap analysis was carried out in PAUP Version 4.0a (Swofford, 2002). The analysis was run for 1000 replicates, and the $50 \%$ majority rule consensus tree was drawn to conclude the bootstrap values. The resulting trees were modified using FigTree v1.4.3 (Rambaut, 2014)

\section{RESULTS AND DISCUSSION}

\section{Morphological features of pennyworts}

All AP cultivars, KP and WP exhibit creeping stolons that are green or yellowish green. The stolons grow 
Table 3: Summary of the qualitative responses in organoleptic assessment

\begin{tabular}{|c|c|c|}
\hline Criteria & \multicolumn{2}{|c|}{$\%$ Respondents and the response parameter } \\
\hline \multirow[t]{3}{*}{ Source of AP } & \multicolumn{2}{|c|}{76 - Market } \\
\hline & \multicolumn{2}{|c|}{16 - Market and home garden grown material } \\
\hline & \multicolumn{2}{|c|}{$\begin{array}{l}08 \text { - Home garden grown material or from rice fields, coconut lands } \\
\text { and natural habitats }\end{array}$} \\
\hline \multirow{3}{*}{$\begin{array}{l}\text { Criteria when } \\
\text { selecting bunches }\end{array}$} & \multicolumn{2}{|l|}{96 - Cleanliness } \\
\hline & \multicolumn{2}{|l|}{85 - Attractive appearance } \\
\hline & \multicolumn{2}{|l|}{93 - Freshness } \\
\hline Preferred culinary & \multicolumn{2}{|l|}{100 - Salad } \\
\hline preparation & \multicolumn{2}{|c|}{08 - Other forms (mellun, porridge and curry) } \\
\hline Preferred special & \multicolumn{2}{|l|}{80 - Maldive-fish } \\
\hline flavour enhancers & \multicolumn{2}{|l|}{100 - lime juice } \\
\hline Preferred AP taste & \multicolumn{2}{|l|}{85 - Peculiar AP bitterness/taste } \\
\hline & \multicolumn{2}{|l|}{82 - Crunchiness/freshness } \\
\hline $\begin{array}{l}\text { Pennywort species/ } \\
\text { cultivar }\end{array}$ & $\begin{array}{l}\% \text { Respondents for preference } \\
\text { classes }\end{array}$ & $\begin{array}{l}\% \text { Respondents for specific } \\
\text { remarks }\end{array}$ \\
\hline \multirow[t]{3}{*}{ GAP1 } & 10 - Highest preference & 90 - Unappealing bunches \\
\hline & \multicolumn{2}{|l|}{80 - Medium preference } \\
\hline & \multicolumn{2}{|l|}{10 - Low preference } \\
\hline \multirow[t]{3}{*}{ GAP2 } & 75 - Highest preference & 82 - Attractive bunches \\
\hline & 10 - Medium preference & $\begin{array}{l}78 \text { - Tidy and clean nature of the } \\
\text { bunches }\end{array}$ \\
\hline & 15 - Low preference & $\begin{array}{l}67 \text { - Easiness for using in } \\
\text { preparations but low taste }\end{array}$ \\
\hline \multirow[t]{3}{*}{ LAP } & 15 - Highest preference & 65 - Rich AP taste \\
\hline & 75 - Medium preference & 50 - Medicinally valuable \\
\hline & 10 - Low preference & 76 - Unappealing bunches \\
\hline \multirow[t]{3}{*}{ SAP } & 30 - Highest preference & $\begin{array}{l}85 \text { - Preference for 'lettuce-margin' } \\
\text { like leaves }\end{array}$ \\
\hline & 35 - Medium preference & 66 - Unappealing bunches \\
\hline & 35 - Low preference & 30 - Low AP taste \\
\hline \multirow[t]{3}{*}{ MAP } & 10 - Highest preference & 85 - Rich AP taste \\
\hline & 70 - Medium preference & 100 - Medicinally valuable \\
\hline & 20 - Low preference & 92 - Unappealing bunches \\
\hline \multirow[t]{3}{*}{ KP } & 15 - Highest preference & 56 - Unappealing bunches \\
\hline & 35 - Medium preference & \\
\hline & 50 - Low preference & \\
\hline \multirow[t]{3}{*}{ WP } & 40 - Highest preference & 40 - Unappealing bunches \\
\hline & 45 - Medium preference & 60 - Unique appealing taste \\
\hline & 25 - Low preference & \\
\hline
\end{tabular}

horizontally connecting the plants. It was observed that the stolons grow fast, and within two weeks, each stolen would produce three to five fully grown leaves that can be harvested for consumption (Table 2). The plants spread and cover the ground rapidly and become a network.
The stolons arise from the leaf axes. Rooting occurs vertically at nodes when they touch with moist soil. KP has a more upright growth pattern. In high nutrient soil, KP grows exceptionally fast and produces large leaves. WP grows well in moist soil and is capable of thriving 
in aquatic habitats. The leaf stalks of WP proliferate to float on the water surface to receive sunlight. The vertical roots of WP emerge from the leaf axils at the nodes. The rootstocks of all pennyworts consist of pale-white hairy rhizomes that grow vertically down (Table 2).

The AP cultivars LAP, GAP1, GAP2, and MAP possess reniform, glabrous leaves with crenate margins (Figures 1A, 1B, 1C, and 1E). WP possesses orbicular shaped, lustrous leaves (Figure 1G) while SAP possesses reniform shaped glabrous leaves with sinuate margin (Figure 1D). KA has compound glabrous leaves with dentate margin (Figure 1F). The leaves of all pennyworts have palmate venation pattern (Figure 1). Among the cultivars, GAP1 and GAP2 have significantly the largest leaves varying from 3-6 cm and 4-9 cm in length/width, respectively (Figures $1 \mathrm{~B}$ and $1 \mathrm{C}$ ). WP, SAP, and LAP possess medium-sized leaves varying from $2-6 \mathrm{~cm}$ in length/width. MAP possesses significantly the smallest leaves with 1-2 cm in length/width (Figure 1). GAP1, GAP2, WP, SAP, and MAP exhibit small white to purple or pink coloured flowers fascicled in umbels at maturity, and each umbel consists of 3-6 flowers. Harvesting of leaves for consumption must be done before the reproductive stage for better texture. All pennyworts except KP show laterally compressed, indehiscent, green to brown colour fruits with thick pericarps. A typical patch from a growing field, a runner, a leaf with the petiole (stalk) at the edible stage, a typical bunch available for selling in the market and adaxial and abaxial sides of a leaf of all pennywort types are displayed in Figure 1.

\section{Organoleptic preference}

\section{Bunch preference}

The colour, leaf size, leaf shape, glossiness of the leaf, aroma and overall preference of the bunch were significantly associated with the pennywort type $\left(\mathrm{p}<0.05, \mathrm{df}=12, \chi^{2}=21.5-51.5\right)$ (Figure 3A). The highest preferred colour of the bunch was reported for GAP2. The least preferred colour was observed for SAP, which has a relatively light green foliage (Figure 1D). However, it was identified that the leafiness was not significantly different among pennyworts $\left(p<0.05, \chi^{2}\right.$ $=17.1)$. The highest preferred leaf size was observed for GAP2, as indicated by $60 \%$ of the respondents, while the highest preferred leaf shape was also recorded for GAP2, (80\% of the respondents). GAP2 also had the highest preferred glossiness (65\% of the respondents). The highest preferred aroma was reported for GAP2 and $\mathrm{KP}$, as indicated by $75 \%$. The highest overall preference was recorded for GAP2 (75\% of the respondents) and the least preference was observed for KP (80\% of the respondents). Although LAP was rated as the highest preferred AP cultivar as a dish, the preference for its bunch is moderate (75\% of the respondents) (Figure $2 \mathrm{~A}$; Figure 4Ai). In bunch preference, the scree plot (Figure 4Aii) indicated that the tasters perceived the colour and glossiness as closely related parameters. The parameters; leaf size, leafiness, and leaf shape were more closely related to each other. The overall preference was more related to leafiness, leaf size, and leaf shape of the bunches (Figure 4Aiii). The principal component (PC) loading status and the respective Eigenvalues are shown in Figures 4Aiii and 4Aiv, respectively.

The present study is of significance because the consumer preference, species delimits of pennyworts, and intra-specific diversity of AP are documented for the first time in scientific literature. Generally, each Sri Lankan person consumes AP salads at least 3-5 times weekly (Balasuriya \& Dharmaratne, 2007; Perera $\&$ Madhujith, 2012). The preparation of AP salads is simple. Some people also add dried tuna (Maldive-fish: a special preparation of seasoned tuna) pieces to improve the taste (Hettiaratchi et al., 2011). Around $24 \%$ people grew the required AP material in their home gardens or backyards, while the majority (76\%) purchased bunches from the market (Table 3). Sri Lankans generally believe (as revealed by all respondents) that MAP is the best AP cultivar with the greatest 'AP taste' and the highest medicinal value. However, the market is dominated by GAP2 because of its ease of growing, cleaning, chopping for cooking, higher yield and attractive appearance of bunches in the market. Because of the large size of the leaves, GAP2 leaf bunches look clean and attractive (Table 3). However, GAP1 is not that attractive, and bunches appear untidy. The leaf size and colour of GAP1 are variable and sometimes even showing yellowish leaves. The present study indicates that people prefer GAP2 bunches, primarily because of its massive leaf size and the attractive leaf shape (Figures $1 \mathrm{~B}$ and $1 \mathrm{C}$ ). MAP and LAP cultivars are less preferred because their bunches are not very tidy looking and often contain sand and clay adhered to the roots and leaves. The leaf bunches of MAP and LAP always has a significant portion of roots attached and it is very difficult to tie up as bunches without roots (Table 3). However, GAP2 arrives at the market as leaf bunches without any roots and no adhered soil. Therefore, people tend to perceive them as clean and free from the harmful pathogens. Also, a majority of the people ( $96 \%$ of the respondents) prefer to spend less time on cleaning and chopping AP leaves. The processing of GAP2 bunches for cooking is the easiest compared to other cultivars increasing the popularity of GAP2. 


\section{Salad preference}

When considering the preference for salad preparations, LAP and WP were the highest preferred types, and SAP was the least preferred (Table 3; Figure 2B; Figure 3B; Figure 4Bi). The colour, aroma, texture, and overall taste of dishes were significantly associated with the type of pennywort ( $p<0.05, \chi^{2}=22.0-53.1$ ). The bitterness was not significantly different among the pennywort types $\left(\mathrm{p}>0.05, \chi^{2}=8.5\right)$. The highest preferred colour of the dish was reported for WP and LAP, as indicated by $58 \%$ of the respondents. The highest preferred aroma
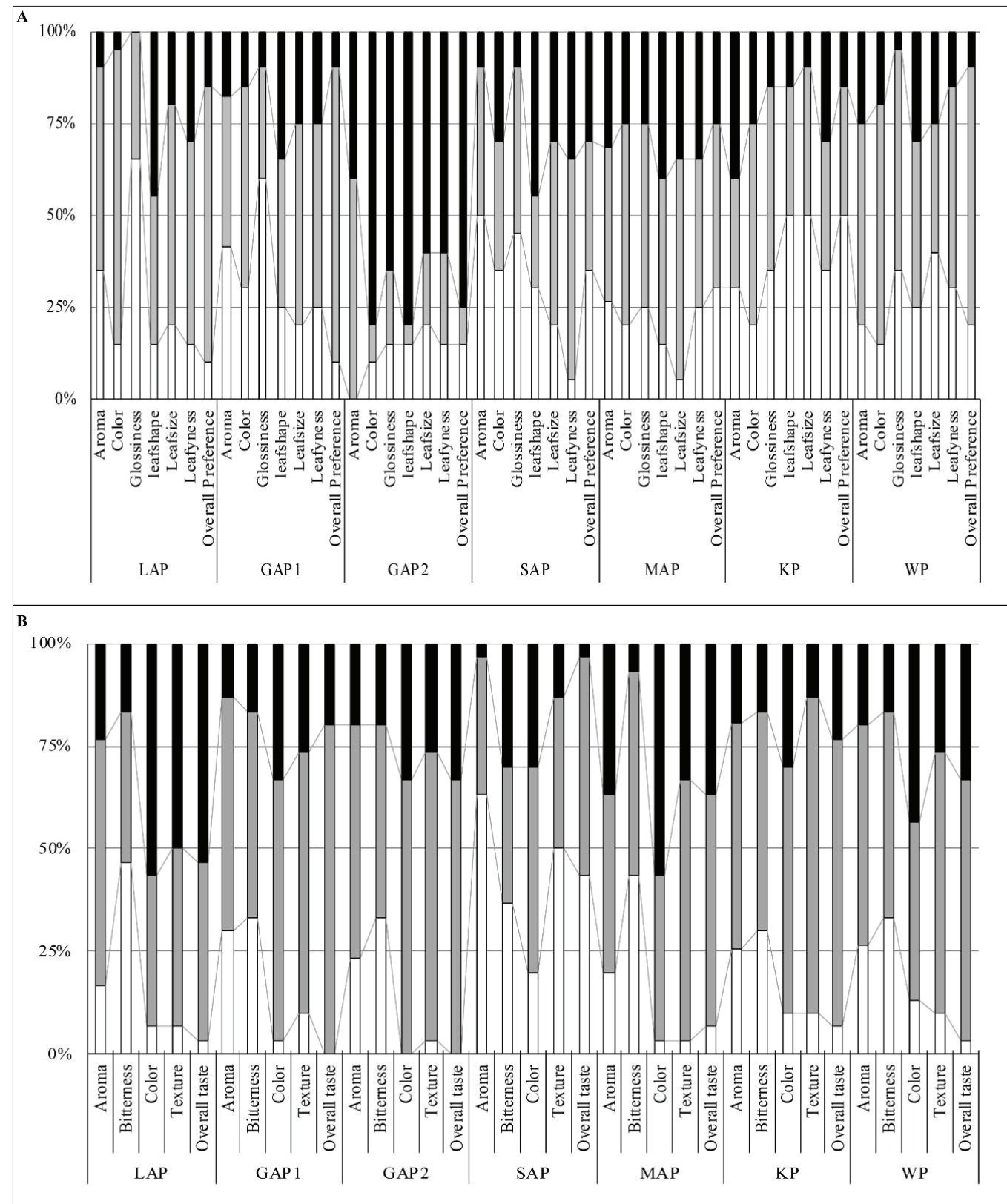

Figure 2: The row percentages of the preference categories calculated in association analysis for each organoleptic parameter and each pennywort. A: preference on bunch; B: preference on salad. Y-axis represents the percentage of respondents. Black portion of the bar: highest preference, ash/grey: moderate preference, white: low preference. 
was reported for WP (36.7\% of the respondents). The best-preferred texture was reported for LAP. The highest overall taste was reported for LAP followed by WP and GAP1 and MAP. The least preferred overall taste was reported for SAP (43.3\% of the respondents) (Table 3; Figure 2B). In dishes, aroma and texture were preferred as an almost single parameter and the overall taste was perceived closely to the aroma and texture (Figure 4Bii).
The bitterness, which has a non-significant association with the pennywort type, was placed in a distant spot indicating that it has a non-significant effect on the overall taste and no association with the other taste parameters assessed (Figure 4Bii). The PC loading status and the respective Eigenvalues are shown in Figures 4Biii and 4Biv, respectively.
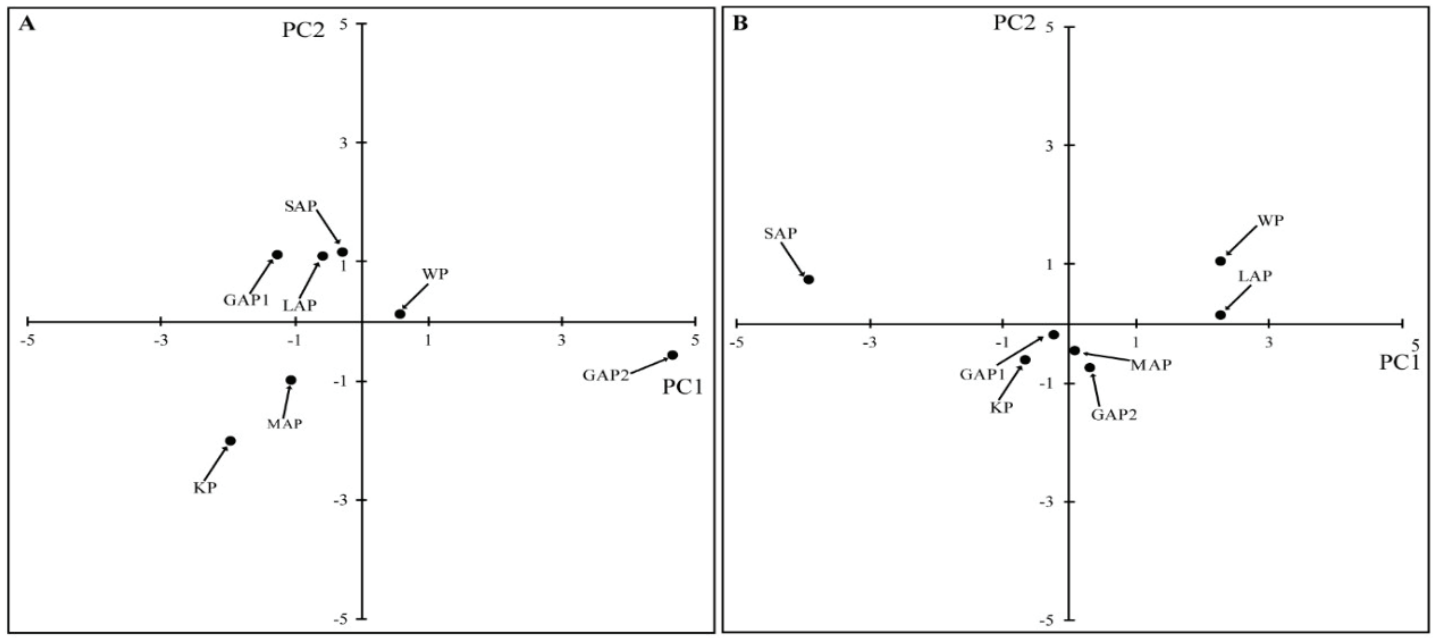

Figure 3: The PC biplots for organoleptic assessments. A: bunch preference; B: salad preference. The weighted scores for each organoleptic parameter were calculated for each pennywort and subjected to PCA separately for bunch preference and salad preference. The two major PCs were used to draw the PC biplots to depict the position of the overall preference for each pennywort.

The highest salad preference for LAP, MAP and WP (Figure 1; Table 3) suggested that Sri Lankans prefer the characteristic slightly bitter, crunchy and flavourful 'AP taste'. Although bunches look gorgeous, AP taste is less intense in GAP2. Therefore, GAP2 is less preferred as a salad. LAP and MAP are highly preferred, and they possess the highest 'AP taste'. WP is not popular compared to AP cultivars among the Sri Lankans as a leafy vegetable. However, WP possesses a unique taste with a pleasing aroma that was highly rated by the taste panellists (Figure 2B).

People specifically prefer LAP and MAP because of the perceived belief of their medicinal values (Table 3). The demand for LAP and MAP is usually catered by harvesting from natural habitats, wet fallowed rice fields, and coconut lands. It is also well known among growers that LAP and MAP are not responding to improved agricultural practices and they are also not profitable to grow as crops because of the small leaf size, profoundly uneven runnering, and entangled growth, which make it difficult to tie up as bunches to sell in the market. Therefore, breeding avenues could be identified to integrate the strong culinary attributes of LAP and MAP into GAP2 to produce a more taste-wise improved AP variety for higher consumer preference. SAP is also unique. The sinuate leaf margin of SAP is significantly similar to the well-known lettuce used in salads worldwide. Although not particularly popular in Sri Lankan cuisines, SAP is ideal for the decoration of food-plates. However, the issue with SAP is that its 'AP taste' is weak, and consumers rated it to the lowest (Figure 3B; Table 3). If SAP can be crossed successively with MAP/LAP, the taste could be improved. Another breeding opportunity is to improve the leaf size of SAP by crossing with GAP2. 


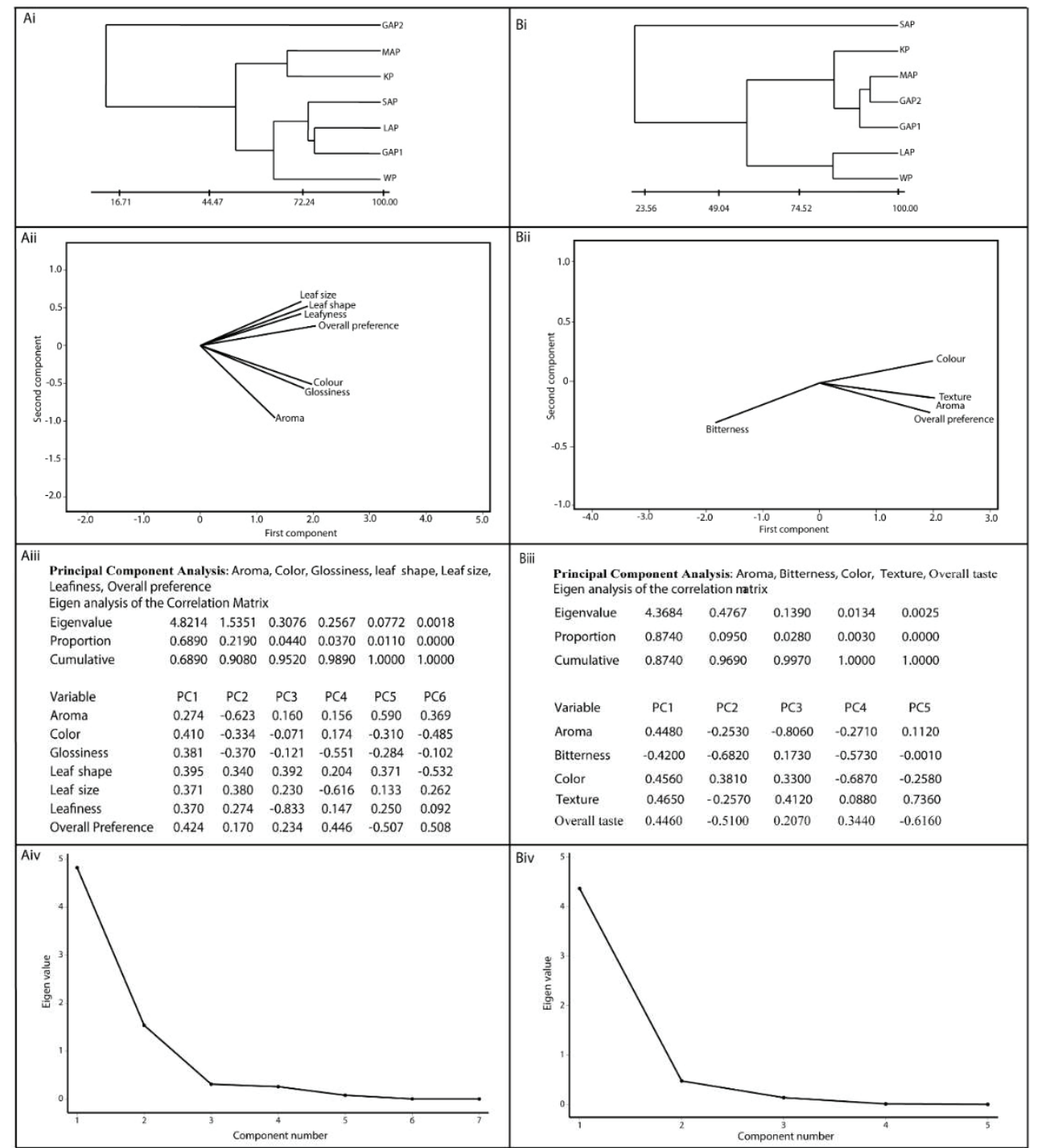

Figure 4: The details of PCA conducted for organoleptic parameters. A: bunch preference; B: Salad preference. i: dendrograms drawn based on all PCs (single linkage and squared euclidian distance); ii: scree plots; iii: PC loading and explanation of variance status in each PC; iv: Eigen value plots.

\section{Phylogenetic relationships among pennywort types in Sri Lanka}

The genetic diversity assessments are sparse for pennyworts, and public nucleotide databases contain very few sequences for the studied markers (Mathur et al., 2000; Van De Wiel et al., 2009) making AP a neglected crop species in molecular biological research. Thus, the present study is important as it explored the variations in DNA barcode sequences with respect to phylogenetic inferences. The WP and KP sequences generated in the present study had a very high similarity (100\%-bit value) with $H$. verticillata and $A$. triphylla, in respective BLAST searches. All AP sequences generated had high similarity to $C$. asiatica sequences reported previously. The AP cultivars grown in Sri Lanka show high genetic similarity. However, the sequence polymorphisms of $r b c L$, atpB-rbcL, and matK-trnT provided a separation of AP cultivars to identify them as unique cultivars (C. asiatica cluster of Figure 5). The C. asiatica crown had two main clades separating medicinally important cultivars and vegetable cultivars. In the clade of vegetable cultivars, two further subclades could be identified based on the leaf size and the shape. Two cultivars with 


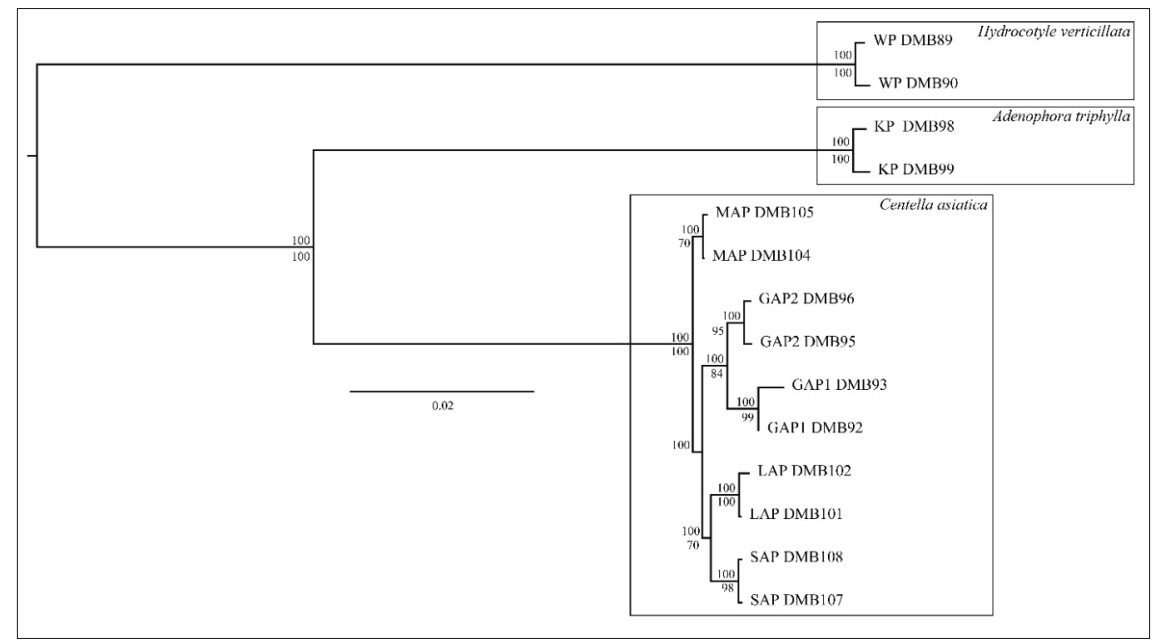

Figure 5: The ML tree depicting the species delimits among C. asiatica, A. triphylla and H. verticillata and the intra-specific diversity of $C$. asiatica. The abbreviations and the voucher numbers are shown in the taxon labels. The bootstrap (bs) and posterior probability (PP) are shown below and above the nodes. The scale bar shows the substitutions per site. The box titles with species names indicate species-specific clusters.

giant leaves cladded together (GAP1 and GAP2) and two other cultivars with small to medium sized leaves were cladded together (LAP and SAP) (Figure 5). The barcodes based on $r b c L$, atpB-rbcL, and matK-trnT loci are depicted in Figure 6. The three species displayed length polymorphism for the two loci, atpB-rbcL, and matK-trnT. All the sequences generated in the present study were deposited in GenBank (Table 1).

The five AP types assessed in the present study are the most popular and well-known pennywort types in Sri Lanka. However, recently, KP and WP are also becoming popular as pennyworts in the country. The origin or the introduction events of KP and WP are not found in published literature. In the present study, the species of WP and KP were confirmed as $H$. verticillata and A. triphylla, respectively (Ohga et al., 2012; USDA, 2018). It can be speculated that WP and KP were introduced to Sri Lanka from East Asia; however, further studies are needed for the confirmation. It is important to note that WP and AP are both considered as pennyworts in Sri Lanka due to the 'pennywort' shape of the leaves. It is quite puzzling to see why KP is regarded as a pennywort because KP leaves are morphologically different (Figure 1B). The most probable reason is when prepared as a salad KP also demonstrates similar culinary attributes to AP and WP.
Through phylogenetic analysis of the pennyworts in Sri Lanka, it was possible to reveal that the domestication/ selection of AP had followed two directions; medicinal value and the food value as indicated by the two major clades in AP crown (Figure 5). Within the food value clade, there was a strong preference and selection for the large leaf size. The intra-specific variation of the AP group in Sri Lanka provide the basis and genetic diversity structure to initiate crossing schemes for the breeding of future cultivars. However, studies on the reproductive biology of AP are required to plan precise crossing schemes. DNA barcodes of the existing cultivars/species of pennyworts were also established as there is a strong demand for AP cultivars in local supermarkets and from Sri Lankan expatriates. The leaf bunches or chopped leaf materials of AP are being exported currently so that DNA barcodes could be printed in the labels/packages to inform the consumers about the specific cultivar contained within the package.

\section{CONCLUSIONS}

The pennyworts in Sri Lanka belong to three species, namely $C$. asiatica, $H$. verticillata, and $A$. triphylla. The consumers prefer to purchase GAP2 leaf bunches because of their large leaf size and appealing look. However, the highest preference for salads is recorded for LAP, MAP, 
and WP compared to other pennyworts. Most of the taste panellists believe LAP and MAP possess rich medicinal values compared to the other pennywort types. The polymorphisms of DNA barcoding loci, $r b c L, a t p B-r b c L$, and matK-trnT provide the basis to define the cultivar identities of $C$. asiatica in Sri Lanka. The present study highlights the need for breeding an AP cultivar with rich taste, high medicinal values, large leaf size and 'sinuate' leaf margin.

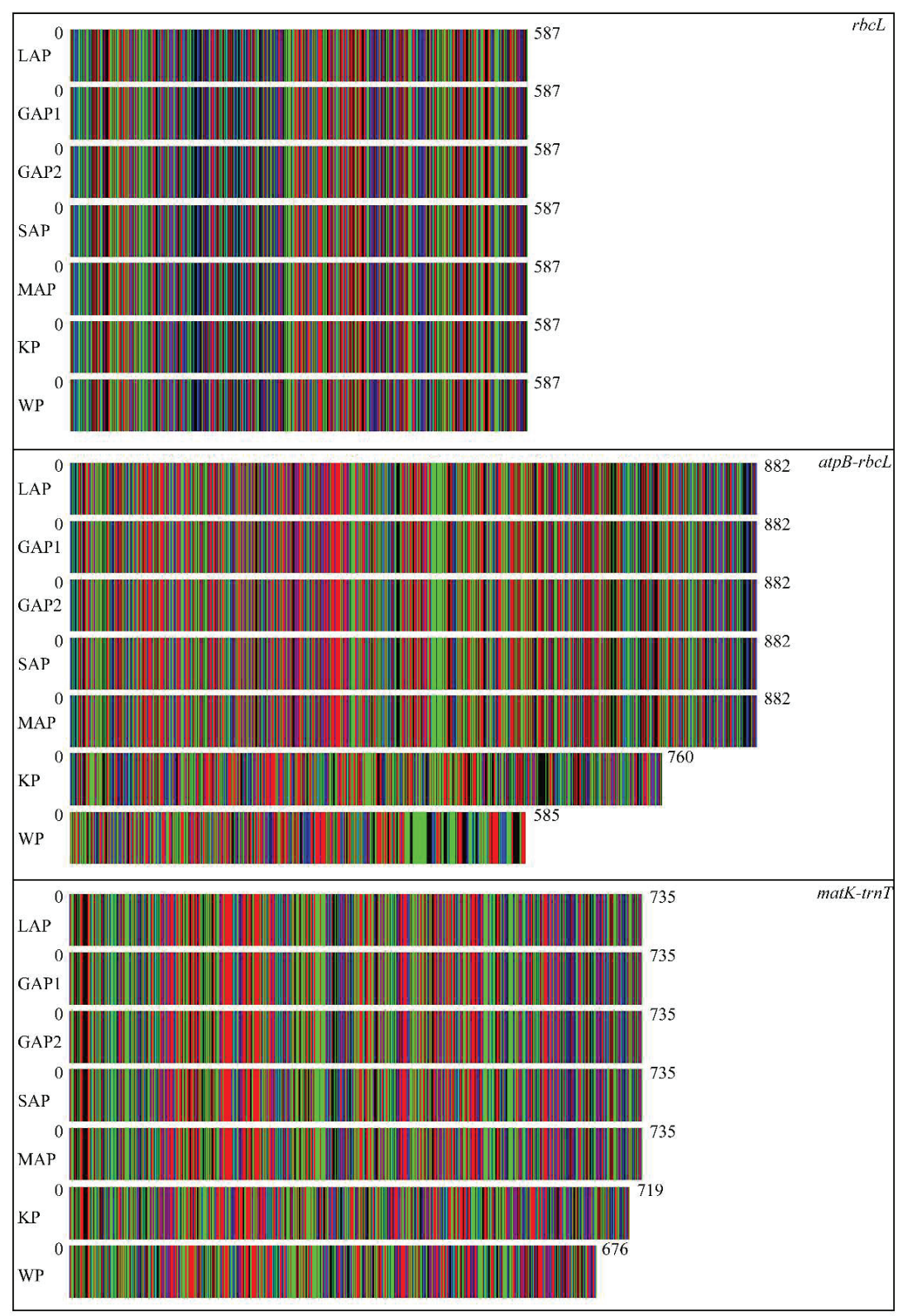

Figure 6: The DNA barcodes for $r b c L$, atpB-rbcL and matk-trnT for Lowland Asiatic Pennywort (LAP); Giant Asiatic Pennywort1 (GAP1); Giant Asiatic Pennywort2 (GAP2); Salad Asiatic Pennywort (SAP); Medicinal Asiatic Pennywort (MAP); Korean Pennywort (KP); and Water Pennywort (WP). The sequences have been submitted to GenBank under the accession numbers: MK905025-MK905079. 


\section{REFERENCES}

Balasuriya B.M. \& Dharmaratne H.R. (2007). Cytotoxicity and antioxidant activity studies of green leafy vegetables consumed in Sri Lanka. Journal of the National Science Foundation of Sri Lanka 35(4): 255-258. DOI: http://doi.org/10.4038/jnsfsr.v35i4.1315

Bandara M.S., Lee E.L. \& Thomas J.E. (2011). Gotu Kola (Centella asiatica L.): an underutilized herb. American Journal of Plant Sciences 5(2): 20-31.

Brinkhaus B., Lindner M., Schuppan D. \& Hahn E.G. (2000). Chemical, pharmacological and clinical profile of the East Asian medical plant Centella asiatica. Phytomedicine 7(5): 427-448.

DOI: https://doi.org/10.1016/S0944-7113(00)80065-3

Cavanaugh J.E. (1997). Unifying the derivations for the Akaike and corrected Akaike information criteria. Statistics and Probability Letters 33(2): 201-208.

DOI: https://doi.org/10.1016/S0944-7113(00)80065-3

Cesarone M.R., Laurora G., De Sanctis M.T., Incandela L., Grimaldi R. \& Marelli C. (1992). The microcirculatory activity of Centella asiatica in venous insufficiency. A double-blind study. Minerva Cardioangiologica 42(6): 299-304.

Chandrika U.G. \& Kumara P.A.A.S.P (2015). Chapter Four Gotu Kola (Centella asiatica): nutritional properties and plausible health benefits. Advances in Food and Nutrition Research 76: 125-157.

DOI: https://doi.org/10.1016/bs.afnr.2015.08.001

Chase M.W., Salamin N., Wilkinson M., Dunwell J.M. \& Kesanakurthi R.P. (2005). Land plants and DNA barcodes: short-term and longterm goals. Philosophical Transactions of the Royal Society of London. Series B, Biological Sciences 360(1462): 1889-1895.

DOI: https://doi.org/10.1098/rstb.2005.1720

Hebert P.D.N., Cywinska A., Ball S.L. \& deWaard J.R. (2003). Biological identifications through DNA barcodes. Proceedings of the Royal Society of London 270(1512): 313-321.

DOI: https://doi.org/10.1098/rspb.2002.2218

Hettiaratchi U.P., Ekanayake S. \& Welihinda J. (2011). Sri Lankan rice mixed meals: effect on glycemic index and contribution to daily dietary fibre requirement. Malaysian Journal of Nutrition 17(01): 97-104.

Hollingsworth P.M., Graham S.W. \& Little D.P. (2011). Choosing and using a plant DNA barcode. PLOS ONE 6(5): e19254.

DOI: https://doi.org/10.1371/journal.pone.0019254

Hoot S.B. \& Taylor W.C. (2001). The utility of nuclear ITS, a LEAFY homolog intron, and chloroplast atpB-rbcL spacer region data in phylogenetic analyses and species delimitation in Isoëtes. American Fern Journal 91(3): 166-177.

DOI: https://doi.org/10.1640/0002-8444(2001)091[0166: TUONIA]2.0.CO;2

Hoot S.B., Culham A. \& Crane P.R. (1995). The utility of atpB gene sequences in resolving phylogenetic relationships: comparison with $r b c L$ and $18 \mathrm{~S}$ ribosomal DNA sequences in the Lardizabalaceae. Annals of the Missouri Botanical Garden 1: 194-207.

DOI: https://doi.org/10.2307/2399877

Huda-Faujan N., Noriham A., Norrakiah A.S. \& Babji A.S. (2007). Antioxidative activities of water extracts of some Malaysian herbs. ASEAN Food Journal 14(1): 61-68.

Huelsenbeck J.P. \& Ronquist F. (2001). MRBAYES: Bayesian inference of phylogenetic trees. Bioinformatics 17(8): 754-755.

DOI: https://doi.org/10.1093/bioinformatics/17.8.754

Incandela L., Cesarone M.R., Cacchio M., De Sanctis M.T., Santavenere C. \& D’Auro M.G. (2001). Total triterpenic fraction of Centella asiatica in chronic venous insufficiency and in high-perfusion microangiopathy. Angiology 52(2 suppl): 9-13.

DOI: https://doi.org/10.1177/000331970105202S03

Jamil S.S., Nizami Q. \& Salam M. (2007). Centella asiatica (linn.) Urban: A review. Natural Product Radiance 6(2): 158-170.

Kress W.J. \& Erickson D.L. (2007). A two-locus global DNA barcode for land plants: the coding $r b c L$ gene complements the non-coding trnH-psbA spacer region. PLoS ONE 2(06): e508.

DOI: https://doi.org/10.1371/journal.pone.0000508

Kumar S., Stecher G. \& Tamura K. (2016). MEGA7: Molecular evolutionary genetics analysis version 7.0 for bigger datasets. Molecular Biology and Evolution 33(7): 1870-1874.

DOI: https://doi.org/10.1093/molbev/msw054

Kumari S.A. et al. (2019). The establishment of the speciesdelimits and varietal-identities of the cultivated germplasm of Luffa acutangula and Luffa aegyptiaca in Sri Lanka using morphometric, organoleptic and phylogenetic approaches. PloS ONE 14(4): e0215176.

DOI: https://doi.org/10.1371/journal.pone.0215176

Levin R.A., Wagner W.L., Hoch P.C., Nepokroeff M., Pires J.C., Zimmer E.A. \& Sytsma K.J. (2003). Family-level relationships of Onagraceae based on chloroplast $r b c L$ and $n d h F$ data. American Journal of Botany 90(1): 107-115. DOI: https://doi.org/10.3732/ajb.90.1.107

Mathur S., Verma R.K., Gupta M.M., Ram M., Sharma S. \& Kumar S. (2000). Screening of genetic resources of the medicinal-vegetable plant Centella asiatica for herb and asiaticoside yields under shaded and full sunlight conditions. The Journal of Horticultural Science and Biotechnology 75(5): 551-554.

DOI: https://doi.org/10.1080/14620316.2000.11511284

Miller M.A., Pfeifferand W. \& Schwartz T. (2010). Creating the CIPRES Science Gateway for inference of large phylogenetic trees. Gateway Computing Environments Workshop (GCE). Available at $h t t p: / / w w w$.ieeexplore.ieee. org/abstract document/5676129, Accessed 4 May 2019. DOI: https://doi.org/10.1109/GCE.2010.5676129

Mitchel A. (2008). DNA barcoding demystified. Austral Entomology 47: 169-173.

DOI: https://doi.org/10.1111/j.1440-6055.2008.00645.x

Nadeeshani H., Wimalasiri K.M.S., Samarasinghe G., Silva R. 
\& Madhujith T. (2018). Evaluation of the nutritional value of selected leafy vegetables grown in Sri Lanka. Tropical Agricultural Research 29(3): 255-267.

DOI: http://doi.org/10.4038/tar.v29i3.8265

Ohga K., Muroi M., Hayakawa H., Yokoyama J., Ito K., Tebayashi S.I., Arakawa R.\& Fukuda T. (2012). Comparative morphology and anatomy of non-rheophytic and rheophytic types of Adenophora triphylla var. japonica (Campanulaceae). American Journal of Plant Sciences 3(6): 805 .

DOI: http://dx.doi.org/10.4236/ajps.2012.36097

Peiris K.H. \& Kays S.J. (1996). Asiatic Pennywort [Centella asiatica (L.) Urb.]: A little-known vegetable crop. Horttechnology 6(1):13-18. DOI: https://doi.org/10.21273/HORTTECH.6.1.13

Perera S.S. (1995). Gotukola-as a cover crop for tea. Tea Quarterly 26: 148-149.

Perera T. \& Madhujith T. (2012). The pattern of consumption of fruits and vegetables by undergraduate students: a case study. Tropical Agricultural Research 23(3): 261-271. DOI: http://dx.doi.org/10.4038/tar.v23i3.4663

Planet P.J. (2006). Tree disagreement: measuring and testing incongruence in phylogenies. Journal of Biomedical Informatics 39(1): 86-102. DOI: https://doi.org/10.1016/j.jbi.2005.08.008

Porebski S., Bailey L.G. \& Baum B.R. (1997). Modification of a CTAB DNA extraction protocol for plants containing high polysaccharide and polyphenol components. Plant Molecular Biology Reporter 15(1): 8-15. DOI: https://doi.org/10.1007/BF02772108

Rambaut A. (2014). FigTree, a graphical viewer of a phylogenetic trees. Available at http://tree. bio. ed.ac. uk/ software/figtree, Accessed 20 March 2019.

Rosen H., Blumenthal A. \& McCallum J. (1967). Effect of asiaticoside on wound healing in the rat. Proceedings of the Society for Experimental Biology and Medicine 125: 279-280.

DOI: https://doi.org/10.3181/00379727-125-32070

Singh B. \& Rastogi R.P. (1969). A reinvestigation of the triterpenes of Centella asiatica. Phytochemistry 8: 917-921.
DOI: https://doi.org/10.1016/S0031-9422(00)85884-7

Singh D., Singh P., Gupta A., Solanki S. \& Sharma E (2012). Qualitative estimation of the presence of bioactive compound in Centella asiatica: an important medicinal plant. International Journal of Life Science and Medical Science 2(1): 5-7.

DOI: https://doi.org/10.5963/LSMR0201002

Singh S., Gautam A., Sharma A. \& Batra A. (2010). Centella asiatica (L.): A plant with immense medicinal potential but threatened. International Journal of Pharmaceutical Sciences and Research 4(2): 9-17.

Sunilkumar S., Parameshwaraiah S. \& Shivakumar H.G. (1998). Evaluation of topical formulations of aqueous extract of Centella asiatica on open wounds in rats. Indian Journal of Experimental Biology 36: 569-572.

Swofford D.L. (2002). PAUP*. Phylogenetic Analysis Using Parsimony (*and Other Methods). Version 4. Sinauer Associates, Sunderland, MA, USA.

Tiwari K.N., Sharma N.C. \& Tiwari V.S.B.D. (2000). Micropropagation of Centella asiatica (L.) a valuable medicinal herb. Plant Cell, Tissue and Organ Culture 63: 179-185.

DOI: https://doi.org/10.1023/A:1010690603095

USDA, NRCS. (2018). The PLANTS Database. Available at http://plants.usda.gov, Accessed 3 May 2019.

Van De Wiel C.C., Van Der Schoot J., Van Valkenburg J.L., Duistermaat H. \& Smulders M.J. (2009). DNA barcoding discriminates the noxious invasive plant species, floating pennywort (Hydrocotyle ranunculoides Lf), from noninvasive relatives. Molecular Ecology Resources 9(4): 1086-1091. DOI: https://doi.org/10.1111/j.1755-0998.2009.02547.x

Wicke S. \& Quandt D. (2009). Universal primers for the amplification of the plastid trnK/matK region in land plants. Anales del Jardín Botánico de Madrid 66(2): 285-288. DOI: https://doi.org/10.3989/ajbm.2231

Yu Q.L., Duan H.Q., Takaishi Y. \& Gao W.Y. (2006). A novel triterpene from Centella asiatica. Molecules 11(09): 661665.

DOI: https://doi.org/10.3390/11090661 